\title{
Nephrolithiasis related to inborn metabolic diseases
}

\author{
Pierre Cochat • Valérie Pichault • Justine Bacchetta • \\ Laurence Dubourg • Jean-François Sabot • \\ Christine Saban • Michel Daudon • Aurélia Liutkus
}

Received: 2 April 2008 /Revised: 8 September 2008 /Accepted: 12 September 2008 /Published online: 21 January 2009

(C) IPNA 2009

\begin{abstract}
Nephrolithiasis associated with inborn metabolic diseases is a very rare condition with some common characteristics: early onset of symptoms, family history, associated tubular impairment, bilateral, multiple and recurrent stones, and association with nephrocalcinosis. The prognosis of such diseases may lead to life threatening conditions, not only because of unabated kidney damage but also because of progressive extra-renal involvement, either in a systemic form (e.g. primary hyperoxaluria type 1, requiring combined liver and kidney transplantation), or in a neurological form (Lesch-Nyhan syndrome leading to automutilation and disability, phosphoribosyl pyrophosphate synthetase superactivity, which is associated with mental retardation). Patients with other inborn metabolic diseases present only with recurrent stone formation, such as cystinuria, adenine phosphoribosyl-transferase deficiency, xanthine deficiency. Finally, nephrolithiasis may be secondarily part of some other metabolic diseases, such as glycogen storage disease type 1 or inborn errors of metabolism leading to Fanconi syndrome (nephropathic cystinosis, tyrosinaemia type 1, fructose intolerance, Wilson disease, respiratory

P. Cochat $\cdot$ V. Pichault $\cdot$ J. Bacchetta $\cdot$ L. Dubourg $\cdot$ J.-F. Sabot $\cdot$

C. Saban $\cdot$ A. Liutkus

Centre de référence des maladies rénales rares \& Inserm U820,

Hospices Civils de Lyon \& Université de Lyon,

Lyon, France

M. Daudon

Laboratoire de Biochimie, Hôpital Necker-Enfants Malades,

Paris, France

P. Cochat $(\square)$

Centre de référence des maladies rénales rares,

Hôpital Femme-Mère-Enfant,

59 boulevard Pinel,

69677 Bron cedex, France

e-mail: pierre.cochat@chu-lyon.fr
\end{abstract}

chain disorders, etc.). The diagnosis is based on highly specific investigations, including crystal identification, biochemical analyses and DNA study. The treatment of nephrolithiasis requires hydration as well as specific measures. Compliance is a major issue regarding the progression of renal damage, but the overall outcome mainly depends on extra-renal involvement in relation to the metabolic defect.

Keywords Nephrolithiasis · Nephrocalcinosis .

Primary hyperoxaluria $\cdot$ Fanconi syndrome $\cdot$ Cystinuria . Purine metabolism · Pyrimidine metabolism · Uric acid . Xanthine $\cdot$ Glycogen storage disease type 1

\section{Introduction}

Nephrolithiasis may occur in many kinds of inborn metabolic disorders, either as the initial symptom (e.g. primary hyperoxaluria, cystinuria) or as a late event (e.g. glycogen storage disease). Urine supersaturation may be related to the biochemical defect itself (oxalate, cystine) or to a secondary disorder (urate, citrate) (Table 1).

Nephrolithiasis associated with inborn metabolic diseases have common characteristics: onset of the disease during childhood, family history (consanguinity in cases of recessive inheritance, urolithiasis among parents in cases of dominant inheritance), associated tubular dysfunction, bilateral stones and/or nephrocalcinosis, multiple and recurrent stones, presence of extra-renal involvement.

\section{Primary hyperoxalurias}

Primary hyperoxaluria $(\mathrm{PH})$ accounts for a wide spectrum of diseases, ranging from occasional stone passage to 
Table 1 Nephrolithiasis associated with inborn metabolic diseases according to presentation and pathophysiology

Nephrolithiasis due to the metabolic defect itself

Nephrolithiasis is usually an initial/early symptom

Primary hyperoxaluria types 1 and 2

Cystinuria

Disorders of purine and pyrimidine metabolism
Nephrolithiasis due to secondary metabolic effect

Nephrolithiasis occurs during the evolution

Glycogen storage disease type 1

Treatment of secondary Fanconi syndrome dramatic systemic oxalosis in infants. Two distinct inherited enzyme defects have been related to $\mathrm{PH} 1$ and $\mathrm{PH} 2$, i.e. alanine:glyoxylate aminotransferase (AGT) and glyoxylate reductase/hydroxypyruvate reductase (GR/HPR), respectively; in addition, patients without $\mathrm{PH} 1$ and $\mathrm{PH} 2$ have been reported. However, PH1 is the most common and the most challenging form.

\section{Epidemiology of primary hyperoxaluria type 1}

PH1 [online Mendelian Inheritance in Man (MIM) 259900] is an autosomal recessive disorder ( 1:120,000 live births per year in Europe), caused by the functional defect of the hepatic, peroxisomal, pyridoxal phosphate-dependent enzyme AGT, leading to oxalate overproduction; the disease occurs because AGT activity is either absent or mistargeted to the mitochondria. Since calcium oxalate is poorly soluble in urine, patients with PH1 usually present with symptoms related to the urinary tract. The risk of stone formation is increased when urine oxalate exceeds $0.4 \mathrm{mmol} / \mathrm{l}$, especially if urine calcium concentration is elevated (i.e. more than $4 \mathrm{mmol} / \mathrm{l}$ ), leading to formation of monohydrated calcium oxalate (whewellite) crystals. The median age of patients when symptoms first appear is 5-6 years, and end-stage renal disease (ESRD) is reached between 25 years and 40 years of age in half of patients [1]. PH1 is responsible for less than $0.5 \%$ of ESRD in children in Europe and $10-13 \%$ in countries with a high rate of consanguineous marriages. Along with progressive decline of glomerular filtration rate (GFR $<30-50 \mathrm{ml} / \mathrm{min}$ per $1.73 \mathrm{~m}^{2}$ ) due to renal parenchymal involvement, continued overproduction of oxalate by the liver and reduced oxalate excretion by the kidneys lead to systemic involvement (named 'oxalosis'), so that bone becomes the major compartment of the poorly soluble oxalate pool (Fig. 1) [2].

\section{Diagnosis of primary hyperoxaluria type 1}

The combination of both clinical and sonographic signs is a strong argument for $\mathrm{PH} 1$, i.e. the association of renal calculi, nephrocalcinosis and renal impairment; in addition, family history may bring additional information. PH1 grossly fits five presentations: (1) infantile form with early nephrocalcinosis and kidney failure; (2) recurrent urolithiasis and progressive renal failure, leading to a diagnosis of PH1 in childhood or adolescence; (3) late-onset form with occasional stone passage in adulthood; (4) diagnosis given by post-transplantation recurrence, and (5) pre-symptomatic subjects with a family history of PH1 [2].

Crystalluria and infrared spectroscopy are of major interest for identification and quantitative analysis of crystals and stones showing whewellite (Fig. 2) [3]. Monohydrated calcium oxalate accounts for $4-5 \%$ of all renal stones in children in France, and most of them are due to PH1.

In the presence of a normal GFR, concomitant hyperoxaluria (urine oxalate $>0.5 \mathrm{mmol} / 1.73 \mathrm{~m}^{2}$ per 24 hours) and hyperglycoluria (urine glycolate $>0.5 \mathrm{mmol} / 1.73 \mathrm{~m}^{2}$ per 24 hours) are indicative of PH1. Normal reference values for spot oxalate: creatinine ratio $(\mathrm{mmol} / \mathrm{mmol})$ are 0.2 at birth, 0.14 at 5 years of age, 0.085 at 10 years of age and 0.06 at 15 years of age.

In patients with well-defined phenotype, genotyping can be proposed in order to screen the most common mutations according to ethnic background. Independent of diagnostic value, mutation analysis may bring information on pyridoxine responsiveness, on complex enzyme phenotype, and, sometimes, on clinical prognosis $[4,5]$. In the presence of atypical presentation, a definitive diagnosis may sometimes require the measurement of AGT activity in liver tissue.

\section{DNA analysis of primary hyperoxaluria type 1}

The $A G X T$ gene is located on chromosome 2q37.3; numerous mutations and polymorphisms have been identified so far, and they play a role either in enzyme trafficking or in clinical/biochemical phenotype. DNA analysis among differ-

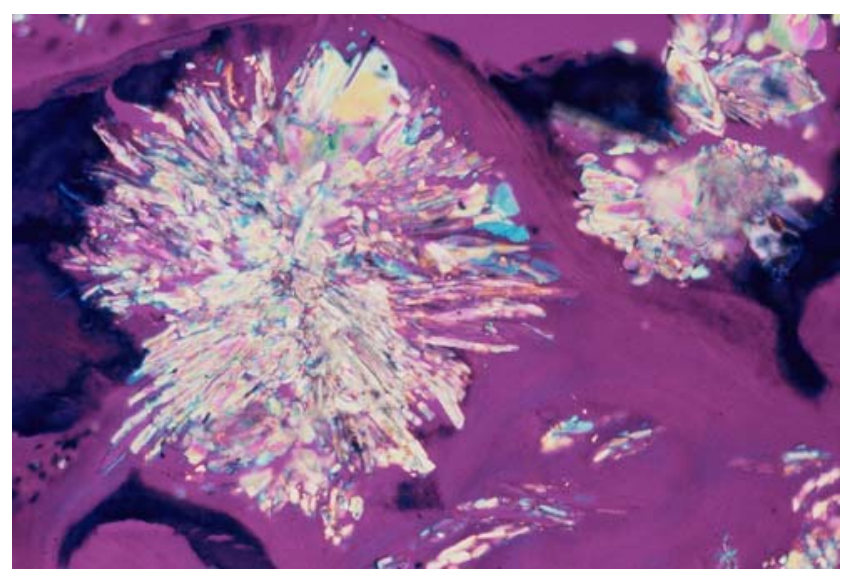

Fig. 1 Bone biopsy in an adolescent with primary hyperoxaluria type 1. Examination under polarised light shows calcium oxalate crystals 
Fig. 2 Infrared spectroscopy examination of a urinary stone.

The spectrum of monohydrated calcium oxalate (whewellite) is shown in a patient with further demonstration of primary hyperoxaluria type 1

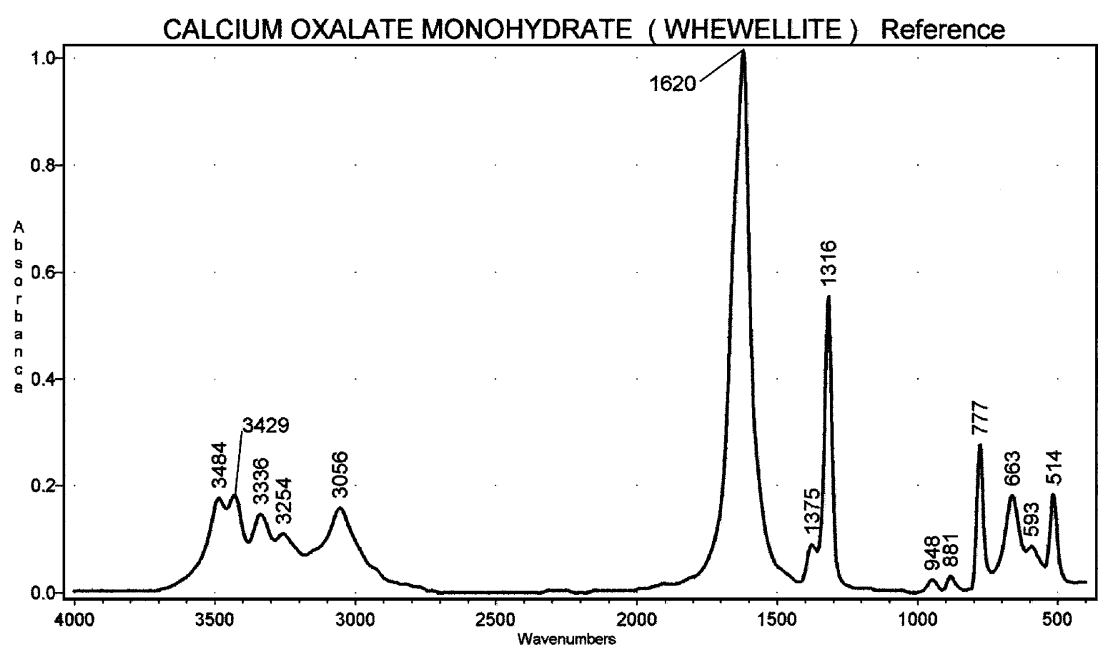

ent ethnic groups has also revealed the presence of specific mutations, founder effects and phenotype-genotype correlations (e.g. North-African, Spanish, Canary Island, Japanese, Turkish, and Pakistani populations) (review in [2, 4]). Prenatal diagnosis can be performed from DNA obtained from chorionic villi or amniocytes.

Treatment of primary hyperoxaluria type 1

Conservative measures should be started as soon as the diagnosis has been made, or even suspected. The aims are to increase calcium oxalate urinary solubility and to decrease oxalate production. Treatment should be initiated with high fluid intake (2-3 $1 / \mathrm{m}^{2}$ per day), aiming at urine dilution by day and night, that may require tube feeding in young children but often fails due to non-compliance. Inhibitors of calcium oxalate crystallisation, such as citrate (potassium or sodium citrate, $100-150 \mathrm{mg} / \mathrm{kg}$ per day in 3-4 divided doses) or phosphate (orthophosphate, $20-60 \mathrm{mg} / \mathrm{kg}$ per day in 3-4 divided doses), are mandatory in order to decrease calcium absorption, and therefore calciuria, and to decrease growth and agglomeration of calcium oxalate crystals. Diuretics require careful management: frusemide will increase urine output with the risk of an increased calciuria, whereas the diuretic effect of thiazides is less marked but is associated with an appreciable decrease in calcium excretion. Restriction of dietary oxalate intake has limited influence on the disease.

Pyridoxine sensitivity (i.e. $>30 \%$ reduction of urinary oxalate excretion) is found in $10-30 \%$ of $\mathrm{PH} 1$ patients, so that it must be tested early at a dose of $5-10 \mathrm{mg} / \mathrm{kg}$ per day according to urinary oxalate (review in [2]). Response to pyridoxine may, therefore, help to preclude or delay the progression to ESRD; the patients most likely to respond are those with homozygous Gly170Arg or Phe152Ile mutations, who also experience preserved renal function over time under adequate treatment [5].
The treatment of stones should avoid open and percutaneous surgery, because further renal lesions will alter GFR. The use of ureteroscopy and ureteral JJ stent is very helpful. Extra-corporeal shock-wave lithotripsy is an available option for selected patients, but mobilisation of extensive parenchymal crystal deposits in the case of nephrocalcinosis may induce parenchymal scarring.

Conventional haemodialysis is not suitable for patients who have reached ESRD, because it cannot overcome the continuous excess production of oxalate, so that there are limited indications [2]: (1) if the diagnosis of PH1 has not been established; (2) in small children with infantile oxalosis waiting for organ transplantation; (3) in preparation for kidney transplant, whether before of after liver transplantation, in order to deplete oxalate from the body; (4) following isolated kidney or combined liver-kidney transplantation with any delay in achieving optimal renal function, as a temporary adjunct in the case of high oxalate burden, or with transient loss of transplant function; (5) very exceptionally, in older patients if the only alternative is no dialysis; (6) in developing countries, in the absence of appropriate organ transplantation.

Liver transplantation is a form of gene therapy as well as enzyme replacement therapy as it will supply the missing enzyme in the correct organ (liver), cell (hepatocyte) and intracellular compartment (peroxisome) [6]. The ultimate goal of organ replacement is to change a positive whole-body accretion rate into a negative one by reducing endogenous oxalate synthesis and providing good oxalate clearance via either native or transplanted kidney. The largest experience has been obtained with a synchronous combined liver-kidney transplantation, leading to acceptable results. The option of a metachronous procedure (liver transplantation followed by kidney transplantation) should be kept in mind according to local experience and when the prospective waiting time is 
long enough to jeopardise both patient quality of life and survival (review in [2]).

Prospects for restoration of defective enzymatic activity through the use of chemical chaperones and hepatocyte cell transplantation, or recombinant gene therapy for enzyme replacement is encouraging for correcting the underlying genetic defect without exposure to the life-long risks associated with organ transplantation [7].

\section{Primary hyperoxaluria type 2}

PH2 (MIM 260000) has been documented in fewer than 50 patients and is characterised by the absence of GR/HPR activity both in the liver and lymphocytes. There is evidence for autosomal recessive transmission, and the gene GRHPR has been located on chromosome 9cen [8].

The median age at onset is 1-2 years, and the classical presentation is urolithiasis (whewellite), including hematuria and obstruction, but stone-forming activity is lower than in PH1. GFR is usually maintained during childhood, and systemic involvement is exceptional [9].

In the presence of hyperoxaluria without hyperglycoluria, a diagnosis of $\mathrm{PH} 2$ should be considered, especially when AGT activity is normal. However, hyperoxaluria in $\mathrm{PH} 2$ tends to be less pronounced than in PH1. The biochemical hallmark is the increased urinary excretion of L-glycerate, but the definitive diagnosis requires DNA analysis and screening of the most frequent mutation (c.103delG).

The overall long-term prognosis is better than for PH1. ESRD occurs in $12 \%$ of patients, between 23 years and 50 years of age. As in PH1, supportive treatment includes high fluid intake, crystallisation inhibitors and prevention of complications. Kidney transplantation has been performed in some patients, often leading to recurrence, including hyperoxaluria and L-glycerate excretion [9].

\section{Inborn errors of amino acid metabolism}

The tubular reabsorption rate of most amino acids approximates $99 \%$, so that their global clearance ranges between $0.5 \mathrm{ml} / \mathrm{min}$ and $2.5 \mathrm{ml} / \mathrm{min}$. They use active trans-tubular transport, which is usually associated with active sodium transport; such tubular transport may be specific to either one single amino acid (e.g. glycine, histidine) or to a group of amino acids (e.g. cystine, lysine, ornithine and arginine). There are some physiological variations in amino acid reabsorption, such as physiological immaturity (iminoglycinuria or cystinuria-lysinuria during the first 6 months of life) or circadian rhythm (increased urinary elimination during daytime and after each meal).
Fanconi syndrome

Hyperaminoaciduria (mainly histidine, glycine, serine, alanine and glutamine) is a marker of proximal tubular dysfunction together with variable increased urinary excretion of glucose, phosphate, bicarbonate, potassium, calcium, uric acid, carnitine, etc. Such Fanconi syndrome may either be primary (idiopathic primary Fanconi syndrome), or it may occur secondarily to various inherited metabolic disorders, i.e. cystinosis (cystinosin), tyrosinaemia type 1 (fumarylacetoacetate hydrolase), fructose intolerance (fructose 1,6-bisphosphate aldolase), Wilson disease (copper-transporting $\mathrm{P}$ type ATPase, $A T P 7 B$ gene), glycogen storage disease type 1 (glucose-6-phosphatase), respiratory chain disorders, Fanconi-Bickel syndrome (GLUT-2), lysinuric protein intolerance ( ${ }^{+}$LAT1 protein encoded by SLC7A7 gene), etc.

In such condition, nephrolithiasis/nephrocalcinosis can be secondary to either hypercalciuria or conservative measures of Fanconi syndrome, including phosphate and vitamin $\mathrm{D}$ that may be responsible for repeated episodes of iatrogenic hypercalciuria.

\section{Cystinuria}

Cystinuria (MIM 220100) is an autosomal recessive inherited aminoaciduria that leads to recurrent nephrolithiasis with a prevalence between 1 in 2,500 and 1 in 100,000; cystine represents $4-8 \%$ of all renal stones in children in France [3]. In this disease, the epithelial transport of dibasic amino acids (cystine, ornithine, arginine and lysine) by the proximal tubule and the small intestine is impaired. However, because of its poor solubility at normal or low urinary $\mathrm{pH}$, only cystine $(1 \mathrm{mmol}=250 \mathrm{mg})$ results in urinary precipitation and recurrent calculi, e.g. at a $\mathrm{pH}$ of 7 , the solubility threshold of cystine is $1 \mathrm{mmol} / 1$ and $2 \mathrm{mmol} / \mathrm{l}$ at a $\mathrm{pH}$ of 7.5 .

Type A disease ( $45 \%$ of patients with cystinuria) is found in families in whom heterozygotes are unaffected and is caused by mutations of SLC $3 A 1$ on chromosome 2 p21 (glycoprotein rBAT protein), whereas type B (53\% of patients with cystinuria) is caused by mutations of SLC7A9 on chromosome $19 \mathrm{q} 12-13\left(\mathrm{~b}^{0,+}\right.$ AT protein), where $80-90 \%$ of heterozygotes demonstrate dibasic aminoaciduria $[10,11]$. Type $\mathrm{AB}$ is found in $2 \%$ of patients with cystinuria, with one mutation in each gene. Both proteins belong to the family of light subunits of heteromultimeric amino acid transporters. Patients may carry either homozygous or compound heterozygous mutations. In addition, there are some reports of patients with the hypotonia-cystinuria syndrome, which is caused by micro-deletions of two contiguous genes, SLC 3A1 and PRELP, on chromosome 2; patients present with generalised hypotonia at birth, failure to thrive, growth retardation and cystinuria type A [12]. 
Certain patients may develop staghorn calculi at young ages, while, in others, the first stone may form in the second or third decade of life, but stone events do not correlate with the urinary excretion of amino acids. Indeed, some infants may exhibit a severe form of cystinuria with transient renal impairment then followed by a partial resolution by 2-4 years of age; this may be due to an increased expression of SLC $3 A 1$ mRNA in postnatal versus fetal kidney [13]. Later in life, cystinuria phenotype seems more severe in male patients than in female patients [11]. In the long term, renal function may be impaired in some patients, mainly those who have not complied with treatment; such an outcome is never due to extensive nephrocalcinosis but to repeated episodes of obstruction and infection.

Cystinuria may be diagnosed by the finding of hexagonal crystals (Fig. 3), a stone, or by increased urinary cystine levels. Quantitative determination of urinary amino acids by ion exchange chromatography usually shows levels of cystine above $100 \mu \mathrm{mol} / \mathrm{mmol}$ creatinine (normal < 30), together with isolated increase of the other dibasic amino acids. A prenatal approach to cystinuria has been suggested by the presence of hyperechoic colon during the third trimester of pregnancy, which may be due to the presence of large amounts of cystine in the colon wall [14].

Cystine stones are often resistant to extra-corporeal shock-wave lithotripsy, so that percutaneous surgery and ureteroscopy are the preferred techniques for stone extraction. Local treatment using percutaneous nephrostomy together with in-situ infusion of bicarbonate and $\mathrm{N}$ acetylcysteine may allow stone dissolution in selected patients [15]. The medical preventive management includes (1) high fluid intake $\left(1.5-2 \mathrm{l} / \mathrm{m}^{2}\right.$ per day) well distributed over day- and night-time; (2) limited sodium intake, because of competition transport of sodium against amino acids at the apical side of the tubular cell; (3) urine alkalinisation using orally administered potassium citrate

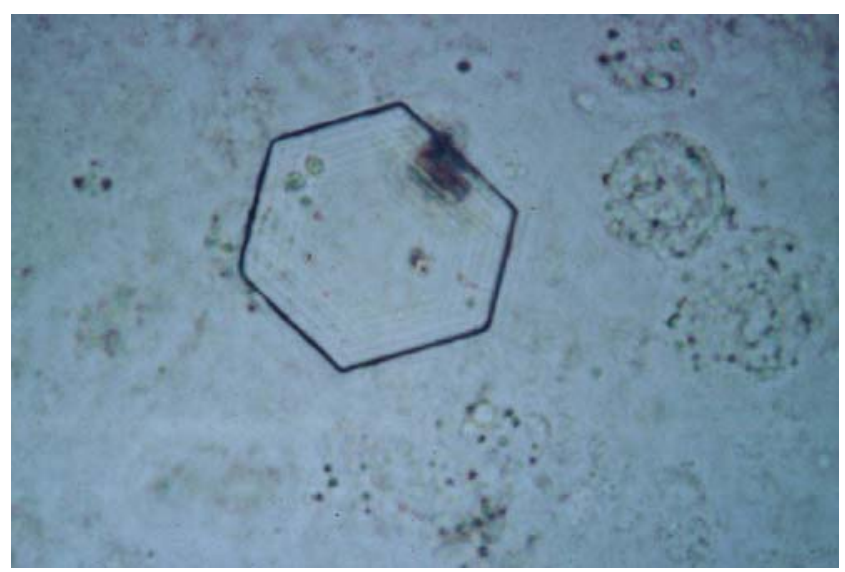

Fig. 3 Examination of urinary sediment discloses a hexagonal crystal of cystine (or sodium bicarbonate); (4) low protein diet in order to limit methionine (precursor of cystine)-rich food (eggs, fish, meat, cheese); (5) when such measures are ineffective in preventing stone recurrence or dissolving pre-existing stones, agents such as $\alpha$-mercapto-propionylglycine (tiopronine, $20 \mathrm{mg} / \mathrm{kg}$ per day) or D-penicillamine $(20 \mathrm{mg} / \mathrm{kg}$ per day) are capable of forming highly soluble mixed disulphides with cystine moieties, especially when cystine excretion is more than $3 \mathrm{mmol}$ per day; such components are 50-times more soluble than cystine $[16,17]$. The follow-up of these patients is based on urine volume (target urine density $<1010$ ), urine $\mathrm{pH}($ target $7.5<\mathrm{pH}<8$ ), free urine cystine concentration (target $<1 \mathrm{mmol} / \mathrm{lor}<100 \mu \mathrm{mol} / \mathrm{mol}$ creatinine), renal ultrasonography and, sometimes, urinary sodium (in order to estimate sodium intake) and crystal volume assessment $\left(\operatorname{target}<3,000 \mathrm{\mu m}^{3} / \mathrm{mm}^{3}\right)$ [18]. Therefore, the treatment must be personalised, and the amount of drug required is dependent on body size.

\section{Inborn errors of purine and pyrimidine metabolism}

Inborn errors of purine and pyrimidine metabolism may be associated with nephrolithiasis of various composition and pathophysiology (Table 2, Fig. 4). They represent $1-3 \%$ of renal stones in children in France [3]. All these calculi are primarily radiolucent, but they can be identified by ultrasound, which usually does not show any kind of nephrocalcinosis.

Most inborn errors of purine and pyrimidine metabolism are characterised by hyperuricosuria, but they are also characterised by calcium stone formation; uric acid excretion rate decreases from childhood towards adulthood and varies with age (normal urinary uric acid is less than $100 \mu \mathrm{mol} / \mathrm{kg}$ per day; normal urate:creatinine ratio (in mmol:mmol) ranges from 1.6 in infants to 0.4 in adolescents), and the highest fractional excretion is found in neonates. Indeed, hyperuricosuria per se enhances calcium oxalate precipitation by lowering its solubility [19]. In addition, urate crystals induce heterogeneous nucleation of calcium oxalate, and hyperuricosuria can adsorb urinary inhibitors of calcium crystallisation [20]. Many children with isolated hyperuricosuria may present with haematuria without evidence of stones, but patients with inborn errors of purine and pyrimidine metabolism exhibit extra-renal involvement, which is a major part of the prognosis of the disease [21].

The solubility of uric acid is dependent on urine $\mathrm{pH}$, so that alkalinisation (aiming at a $\mathrm{pH}$ between 6 and 7) may prevent further stone formation or allow the dissolution of existing calculi. This should be added to hydration, aiming at a target concentration of urinary uric acid below 2.5 $\mathrm{mmol} / \mathrm{l}$. In addition, a low purine/nucleoprotein diet is recommended. 
Table 2 Pathophysiology and stone composition of inborn defects of purine and pyrimidine metabolism ( $P R P P$ phosphoribosyl pyrophosphate, $H G P R T$ hypoxanthine-guanine phosphoribosyl transferase, APRT adenine phosphoribosyl transferase, $U M P$ uridine monophosphate)

\begin{tabular}{|c|c|c|c|c|}
\hline \multirow[t]{2}{*}{ Stone composition } & \multicolumn{4}{|l|}{ Pathophysiology } \\
\hline & $\begin{array}{l}\text { Defect in purine } \\
\text { nucleotide synthesis }\end{array}$ & $\begin{array}{l}\text { Defect in purine } \\
\text { catabolism }\end{array}$ & $\begin{array}{l}\text { Defect in } \\
\text { purine salvage }\end{array}$ & $\begin{array}{l}\text { Defect in pyrimidine } \\
\text { metabolism }\end{array}$ \\
\hline Uric acid & PRPP synthetase superactivity & & HGPRT deficiency & \\
\hline Xanthine & & Xanthine oxidase deficiency & & \\
\hline 2,8-Dihydroxyadenine & & & APRT deficiency & \\
\hline Orotic acid & & & & UMP synthase deficiency \\
\hline
\end{tabular}

${ }^{\text {a }}$ No nephrolithiasis

Phosphoribosyl pyrophosphate synthetase superactivity

Phosphoribosyl pyrophosphate (PRPP) synthetase superactivity (MIM 300661) is of X-linked inheritance. In pedigrees with associated sensorineural deafness, heterozygous female subjects have been found with gout and hearing impairment [22].

The disease usually shows in young male patients with gouty arthritis and uric acid nephrolithiasis, sometimes leading to ESRD. Plasma uric acid is increased and may reach 600-900 $\mu \mathrm{mol} / \mathrm{l}$ (normal adult values $170-320 \mu \mathrm{mol} / \mathrm{l}$ ), and urine uric acid is also increased so that the urinary uric acid to creatinine ratio approximates $2.5 \mathrm{mmol} / \mathrm{mmol}$ (normal adult values $0.2-0.3 \mathrm{mmol} / \mathrm{mmol})$. Such uric acid overproduction may appear during infancy, together with neurological abnormalities, i.e. sensorineural deafness, hypotonia, motor delay, ataxia and autistic features [22].

The enzyme forms PRPP from ribose-5-phosphate and adenosine triphosphate (ATP) (Fig. 4). PRPP synthetase is highly regulated; various genetic regulatory and catalytic defects may lead to superactivity, resulting in increased generation of PRPP [21]. PRPP synthetase superactivity is one of the few examples of enhanced enzyme activity. The pathophysiology of neurological involvement is unknown.

The diagnosis is based on kinetics studies of the enzyme on erythrocytes and cultured fibroblasts in a limited number of
Fig. 4 Simplified pathways of purine metabolism

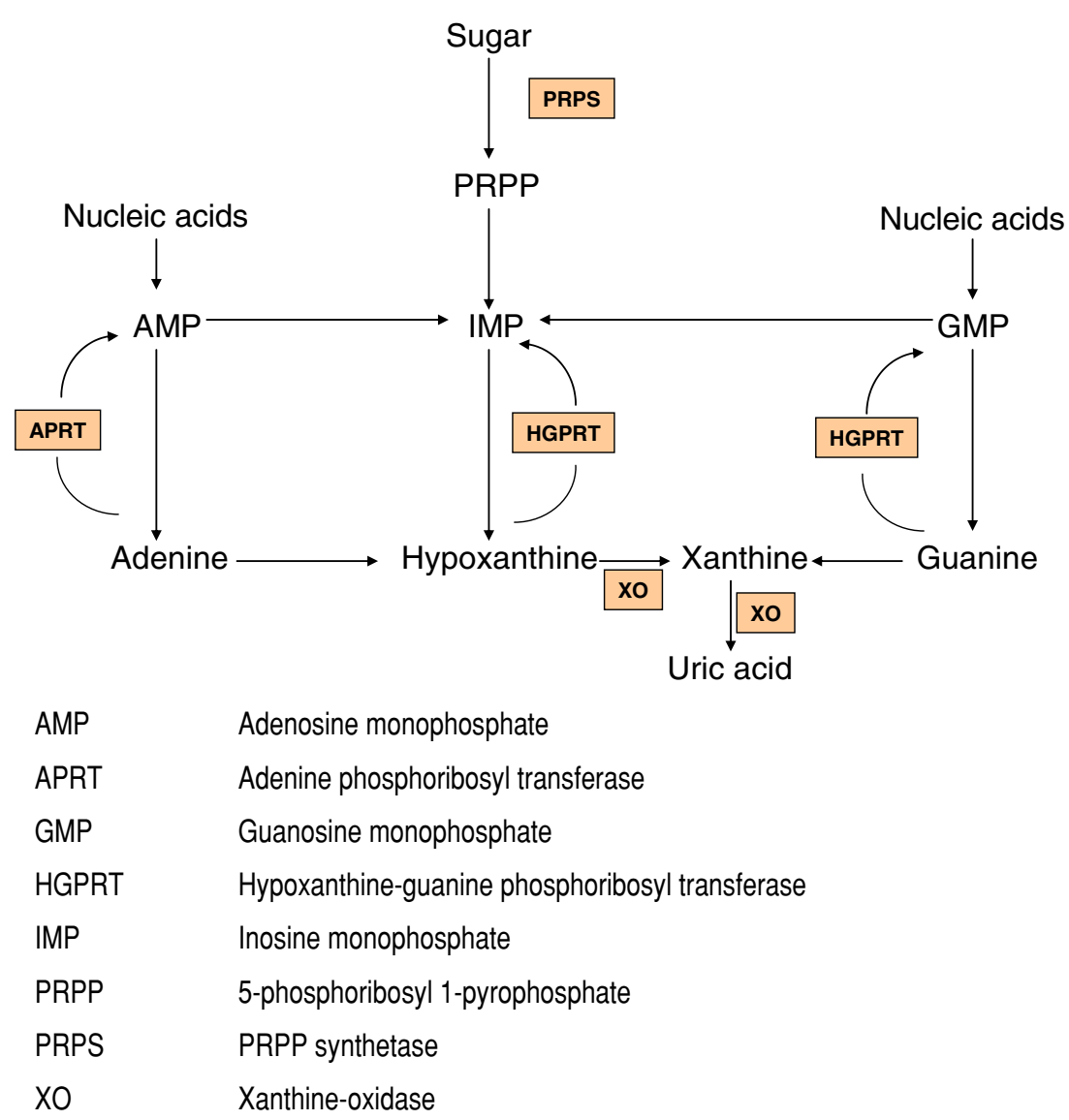


laboratories. The disease should be differentiated from partial HGPRT deficiency, which may give similar clinical signs.

The treatment is based on allopurinol, which inhibits xanthine oxidase and results in a decrease in the production of uric acid and its replacement by both hypoxanthine and xanthine (Fig. 4), which are more soluble than uric acid. The initial dosage is $10-20 \mathrm{mg} / \mathrm{kg}$ per day for children and $2-10 \mathrm{mg} / \mathrm{kg}$ per day for adults, which should be further adjusted to the minimum required to maintain normal plasma uric acid concentration, and reduced for patients with impaired renal function. In some patients with major increase in de novo synthesis, xanthine calculi can be formed during allopurinol therapy [23]. Additional measures to prevent crystallisation are recommended: a low purine diet (free of organ meats, fish such as anchovy, herring, mackerel, salmon, sardines and tuna, dried beans and peas), high fluid intake and alkalinisation aiming at a urinary $\mathrm{pH}$ of 6.0 to 7.0 (sodium bicarbonate, potassium citrate or other citrate mixtures). Adequate control of plasma uric acid (target $<400 \mu \mathrm{mol} / \mathrm{l}$ ) is required in order to control gout and renal involvement, but it has no influence on neurological outcome.

Hypoxanthine-guanine phosphoribosyl transferase deficiency: Lesch-Nyhan syndrome

Deficiency of hypoxanthine-guanine phosphoribosyl transferase (HGPRT) activity is an inborn error of purine metabolism associated with uric acid overproduction (Fig. 4) and various degrees of neurological involvement, depending on the degree of enzyme deficiency (MIM 300322). The prevalence is estimated at 1 in 380,000 live births in Canada and 1 in 235,000 in Spain [24].

Neurological manifestations include severe action dystonia, choreo-athetosis, ballismus, cognitive and attention deficit, and self-destructive behaviour (biting of fingers and lips leading to mutilating loss of tissue). The most severe presentations are known as Lesch-Nyhan syndrome; patients are healthy at birth, and diagnosis can be accomplished when psychomotor delay becomes apparent. Whereas most patients have an intelligence quotient (IQ) around 50 , some display normal intelligence. Half of the patients have seizures [21]. Partial HGPRT-deficient patients present these symptoms with a different intensity, and in the least severe forms symptoms may be either unapparent or limited to gout.

Uric acid overproduction is found in all HGPRTdeficient patients and is associated with nephrolithiasis and gout. Orange crystals may be identified in diapers during the first weeks of life, and some patients may show neonatal acute renal failure due to crystal nephropathy [25]. In the absence of specific treatment, patients exhibit repeated uric acid nephrolithiasis, with the risk of obstruction and further chronic renal insufficiency.
Overproduction of uric acid is due to increased quantity of PRPP, which is not utilised at the level of HGPRT but leads to de novo synthesis (Fig. 4). However, the pathophysiology of neurological involvement is not clear and may be based on dopaminergic dysfunction.

The disease is of $\mathrm{X}$-linked recessive inheritance, thus boys are affected whereas girls are usually asymptomatic carriers. Human HGPRT is encoded by a single structural gene at Xq26. To date, more than 300 mutations have been identified.

The diagnosis is based on clinical and biochemical findings [hyperuricaemia (concentrations up to $1,000 \mu \mathrm{mol} /$ 1) and hyperuricosuria (concentrations of $150-850 \mu \mathrm{mol} / \mathrm{kg}$ per $24 \mathrm{~h}$ ), together with psychomotor delay], and enzymatic (determination of HGPRT activity in red blood cells or fibroblasts) and molecular tests [24]. Molecular diagnosis allows faster and more accurate carrier and prenatal diagnosis. Prenatal diagnosis can be performed from chorionic villous cells obtained at 10-12 weeks gestation or from amniotic cells obtained by amniocentesis at $15-18$ weeks gestation.

Uric acid overproduction can be managed by allopurinol treatment at a dose of $4-10 \mathrm{mg} / \mathrm{kg}$ per day (without exceeding $300 \mathrm{mg}$ per day because of the risk of oxypurinol crystallisation), with a target concentration of plasma uric acid below $400 \mu \mathrm{mol} / 1$ [26]. Indeed, allopurinol dosage must be carefully adjusted in order to avoid increased urine xanthine and further iatrogenic xanthine crystal formation (normal urine xanthine $0.03 \pm 0.01 \mathrm{mmol} / \mathrm{mol}$ creatinine) [27]. The lack of precise understanding of neurological involvement has precluded the development of useful therapies. Spasticity and dystonia can be managed with diazepam, baclofen, haloperidol and/or barbiturates. In addition, adequate physiotherapy is recommended. Selfinjurious behaviour must be managed by a combination of physical restraints (elbow splints, lip guards and even tooth extraction) and behavioural and pharmaceutical treatments. Some new therapeutic options have been proposed to improve self-mutilation, such as chronic stimulation of the globus pallidus or the oral use of nifedipine. Bone marrow transplantation may restore erythrocyte HGPRT, but it has no influence on neurological symptoms.

\section{Adenine phosphoribosyl transferase deficiency}

The deficiency may lead to clinical manifestations in early childhood, but it can also remain silent for decades (MIM 102600). Symptoms include the passage of crystals, gravel, and stones. Such nephrolithiasis is responsible for abdominal colic, dysuria, haematuria, urinary tract infection, and, sometimes, acute anuric renal failure. 2,8-dihydroxyadenine is found in crystals and stones and can be distinguished from uric acid stones only by infrared spectrophotometry. 
The deficiency results in suppression of adenine (Fig. 4), and adenine is oxidised by xanthine oxidase into 2,8dihydroxyadenine, which is a very poorly soluble compound. Such a deficiency can be complete or partial (only in Japanese patients).

Adenine phosphoribosyl transferase (APRT) deficiency is of autosomal recessive inheritance, and the gene has been located on chromosome 16q24. All Japanese patients carry the same mutation, while approximately 30 mutations have been reported in Caucasians.

The identification of 2,8-dihydroxyadenine requires specific diagnostic tests, i.e. infrared spectrometry, mass spectrometry and X-ray crystallography. The deficit is confirmed by assessment of APRT activity in red blood cells (normal enzyme activity in red blood cells $=15-35 \mathrm{U} / \mathrm{l}$ ) [28].

Allopurinol should be given to patients with symptoms in order to inhibit the formation of 2,8-dihydroxyadenine. In addition, dietary purine restriction and high fluid intake are recommended, but alkalinisation of the urine is not advised, since the solubility of 2,8-dihydroxyadenine is unchanged up to $\mathrm{pH} 9$ [21].

The ultimate outcome depends on renal function at the time of diagnosis, and delayed identification of the disease may lead to chronic renal insufficiency.

\section{Xanthine-oxidase deficiency}

Two deficiencies of xanthine oxidase (or dehydrogenase) are known: isolated hereditary xanthinuria (type 1, with nephrolithiasis) and combined xanthine oxidase and sulphite oxidase deficiency (type 2, with prominent neurological involvement). Isolated xanthine oxidase deficiency (MIM 278300) can be asymptomatic, but one-third of affected patients suffer from kidney stones. Xanthine stones are not visible on X-ray and may appear at any age; some patients also present with myopathy associated with crystalline xanthine deposits.

The metabolic deficiency results in the replacement of uric acid by hypoxanthine and xanthine as the end products of purine catabolism (Fig. 4). The gene of isolated xanthine oxidase deficiency is located on chromosome $2 \mathrm{p} 22$; only two mutations, resulting in a nonsense substitution and a termination codon, have been reported [29].

Plasma concentration of uric acid is low $(<60 \mu \mathrm{mol} / \mathrm{l})$ and may become undetectable if the patient is on a lowpurine diet. Urinary uric acid is dramatically reduced and replaced by hypoxanthine and xanthine. The enzymatic assessment requires liver or intestinal mucosa, the only tissues which normally contain significant amounts of xanthine oxidase [21].

Isolated xanthine oxidase is usually a benign condition, but recurrent renal stones should be prevented by the use of a low-purine diet and by large fluid intake.
Hereditary renal hypo-uricaemia

Familial renal hypo-uricaemia (MIM 220150) is a very rare disease caused by mutations in the SLC22A12 gene [30]. The disease is due to a defect in the tubular reabsorption of urate, such as in Dalmatian dogs, sometimes leading to uric acid nephrolithiasis. Some patients may present with exercise-induced acute renal failure. Prevention of stone formation may be achieved by hydration and alkalinisation.

\section{Glycogen storage disease type 1}

Glycogen storage disease type 1 (GSD-1) is mainly due to a deficiency in the catalytic subunit of glucose-6-phosphatase (GSD-1a or von Gierke disease, MIM 232200, G6PT1 gene mutation, $80 \%$ of all GSD-1) and sometimes to a deficiency of the endoplasmic reticulum glucose-6-phosphate translocase (MIM 232220, GSD-1b, 20\% of GSD-1). Both GSDs involve the liver and the kidney, and patients present with hepatomegaly, short stature, hypoglycaemia, lactacidaemia and hyperlipidaemia; neutropenia and infections are specific of GSD-1b [31]. GSD-1a and GSD-1b are autosomal recessive disorders; the gene encoding glucose-6-phosphatase $(G 6 P C)$ has been identified on chromosome 17q21, and the gene encoding glucose-6- phosphate translocase has been found on chromosome 11q23.

Nephrocalcinosis and nephrolithiasis may occur only during the course of GSD-1 and not in other types of GSD, involving both hypercalciuria/hypocitraturia and hyperuricaemia [31]. Part of the glucose-6-phosphate excess is metabolised by pentose phosphate shunt, therefore leading to hyperuricaemia. In addition, renal distal tubular dysfunction can occur, even in patients with adequate metabolic control, and may lead to a combination of low citrate excretion and hypercalciuria [32]. Normally, urinary citrate excretion increases with age, but, in patients with GSD-1a, both calcium and citrate excretion are inversely correlated with age. Such reduction in citrate excretion may be due to chronic lactic acidosis secondary to deficient glucose production. Indeed, chronic metabolic acidosis is able to increase citrate uptake by the proximal tubular cell in intracellular acidosis and by direct influence in the proximal tubular transport of citrate by the brush border membrane in response to low luminal $\mathrm{pH}[33,34]$. The long-term combination of chronic acidosis and hypercalciuria may explain the relevance of severe osteoporosis in adults with GSD-1a.

Oral citrate supplementation may be able to prevent and ameliorate nephrocalcinosis and the development of nephrolithiasis [32]. Sodium salts should be avoided, to limit additional calcium excretion. In addition, such patients should 
be given allopurinol to control plasma uric acid and thiazides, in order to control hypercalciuria and prevent worsening of osteoporosis.

\section{Other rare conditions associated with nephrolithiasis}

\section{Deficiency of 5-oxoprolinase}

Very few patients have been reported with a hereditary defect in 5-oxoprolinase (MIM 260005), a disorder in the metabolism of glutathione, which is of autosomal recessive inheritance [35]. Renal stone formation may lead to diagnosis, which can also include chronic enterocolitis, hypoglycaemia and mild mental retardation. Patients excrete abnormal amounts of 5-oxoproline. No specific treatment has been proposed, and prognosis remains to be established.

Glucose-galactose malabsorption (disorder of glucose transport)

Severe nephrocalcinosis may be found in glucose-galactose malabsorption (SGLT1 deficiency) in association with hypercalcaemia [36].

\section{3-Methylglutaconic aciduria}

3-Methylglutaconic aciduria (branched-chain organic aciduria, MIM 250950) is characterised by urinary excretion of 3-methylglutaconyl-CoA and 3-methylglutaric acids. Such biochemical abnormality is frequently found during urine organic acid analysis and is often regarded as a marker of mitochondrial disorder. Some patients have been reported with nephrocalcinosis and sometimes medullary cysts [37].

\section{Blue-diaper syndrome}

Blue-diaper syndrome (Drummond syndrome, MIM 211000) is characterised by hypercalcaemia, nephrocalcinosis and indicanuria. The disease is associated with a defect in intestinal tryptophane absorption that leads to blue colouration of the urine after contact with the air. The transmission may be autosomal recessive or X-linked, and the defect may be due to mutations in the LAT2 or TAT1 genes [38].

\section{Conclusion}

Nephrolithiasis related to inherited metabolic diseases is a very rare condition that may require specific measures. However, the overall outcome usually depends on extrarenal involvement in relation to the metabolic defect.

\section{Questions}

\section{(Answers appear following the reference list)}

1. In the presence of hyperoxaluria, the following findings are suggestive of primary hyperoxaluria type 1 :
a. monohydrated oxalate crystals in the urine
b. elevated glycerate in the urine
c. elevated glyoxylate in the urine
d. elevated glycolate in the urine
e. early nephrocalcinosis with GFR impairment

2. Cystinuria

a. is due to a defect in the cystinosin transport protein

b. can give symptoms in any kind of obligate heterozygotes

c. can be symptomatic in infants

d. is often responsible for nephrocalcinosis

e. has poor results for stone treatment with extracorporeal shock-wave lithotripsy

3. Uric acid is the major component of stones in the following diseases:
a. Fanconi syndrome
b. phosphoribosyl pyrophosphate synthetase superactivity
c. Lesch-Nyhan syndrome
d. adenine phosphoribosyl transferase (APRT) deficiency
e. xanthine oxidase deficiency

\section{References}

1. Cochat P, Deloraine A, Rotily M, Olive F, Liponski I, Deries N, on behalf of the Société de Néphrologie and the Société de Néphrologie Pédiatrique (1995) Epidemiology of primary hyperoxaluria type 1. Nephrol Dial Transplant 10 [Suppl 8]:3-7

2. Cochat P, Liutkus A, Fargue S, Basmaison O, Ranchin B, Rolland MO (2006) Primary type 1: still challenging. Pediatr Nephrol 21:1075-1081

3. Daudon M, Jungers P (2004) Clinical value of crystalluria and quantitative morphoconstitutional analysis of urinary calculi. Nephron Physiol 98:31-36

4. Rumsby G, Williams E, Coulter-Mackie M (2004) Evaluation of mutation screening as a first line test for the diagnosis of the primary hyperoxaluria. Kidney Int 66:959-963

5. van Woerden CS, Groothoff JW, Wijburg FA, Annink C, Wanders RJ, Waterham HR (2004) Clinical implications of mutation analysis in primary hyperoxaluria type 1 . Kidney Int 66:746-752

6. Danpure CJ, Rumsby G (1995) Enzymological and molecular genetics of primary hyperoxaluria type 1. Consequences for clinical management. In: Khan SR (ed) Calcium oxalate in biological systems. CRC Press, Boca Raton, pp 189-205

7. Bobrowski AE, Langman CB (2006) Hyperoxaluria and systemic oxalosis: current therapy and future directions. Expert Opin Pharmacother 7:1887-1896 
8. Rumsby G, Sharma A, Cregeen DP, Solomon LR (2001) Primary hyperoxaluria type 2 without L-glycericaciduria: is the disease under-diagnosed? Nephrol Dial Transplant 16:1697-1699

9. Johnson SA, Rumsby G, Cregeen D, Hulton S (2002) Primary hyperoxaluria type 2 in children. Pediatr Nephrol 17:597-601

10. Shekarriz B, Stoller ML (2002) Cystinuria and other noncalcareous calculi. Endocrinol Metab Clin North Am 31:51-77

11. Dello Strologo L, Pras E, Pontesilli C, Beccia E, Ricci-Barbini V, De Sanctis L, Ponzone A, Gallucci M, Bisceglia L, Zelante L, Jimenez-Vidal M, Font M, Zorzano A, Rousaud F, Nunes V, Gasparini P, Palacin M, Rizzoni G (2002) Comparison between SLC3A1 and SLC7A9 cystinuria patients and carriers: a need for a new classification. J Am Soc Nephrol 13:2547-2553

12. Martens K, Heulens I, Meulemans S, Zaffanello M, Tilstra D, Hes FJ, Rooman R, François I, de Zegher F, Jaeken J, Matthijs G, Creemers JW (2007) Global distribution of the most prevalent deletions causing hypotonia-cystinuria syndrome. Eur J Hum Genet 15:1029-1033

13. Boutros M, Vicanek C, Rozen R, Goodyer P (2005) Transient neonatal cystinuria. Kidney Int 67:443-448

14. Brasseur-Daudry M, Garel C, Brossard V, Broux F, Heckettsweiler B, Eurin D (2006) Hyper-echogenic colon: a prenatal sign of cystinuria. Prenat Diagn 26:1254-1255

15. Bertrix L, Canterino I, Martin X, Morin D, Cochat P (2008) Traitement in situ de la lithiase cystinique. Arch Pediatr (in press)

16. Dello Strologo L, Laurenzi C, Legato A, Pastore A (2007) Cystinuria in children and young adults: success of monitoring free-cystine urine levels. Pediatr Nephrol 22:1869-1873

17. Joly D, Rieu D, Méjean A, Gagnadoux MF, Daudon M, Jungers $P$ (1999) Treatment of cystinuria. Pediatr Nephrol 13:945-950

18. Daudon M, Cohen-Solal F, Barbey F, Gagnadoux MF, Knebelman B, Jungers P (2003) Cystine crystal volume determination: a useful tool for the management of cystinuric patients. Urol Res 31:207-211

19. Pak CY, Waters O, Arnold L, Holt K, Cox C, Barilla D (1977) Mechanism for calcium urolithiasis among patients with hyperuricosuria. J Clin Invest 59:426-431

20. Zerwekh JE, Holt K, Pak CY (1983) Natural urinary macromolecular inhibitors: attenuation of inhibitory activity by urate salts. Kidney Int 23:838-841

21. van den Berghe G, Vincent MF, Marie S (2006) Disorders of purine and pyrimidine metabolism. In: Fernandes J, Saudubray JM, van den Berghe G, Walter JH (eds) Inborn metabolic diseases: diagnosis and treatment. Springer, Heidelberg, pp 433-449

22. Becker MA, Puig JG, Mateos FA, Jimenez ML, Kim M, Simmonds HA (1988) Inherited superactivity of phosphoribosylpyrophosphate synthetase: association of uric acid overproduction and sensorineural deafness. Am J Med 85:383-390

23. Kranen S, Keough D, Gordon RB, Emmerson BT (1985) Xanthine-containing calculi during allopurinol therapy. J Urol 133:658-659

24. Torres RJ, Prior C, Puig JG (2007) Efficacy and safety of allopurinol in patients with hypoxanthine-guanine phosphoribosyl-transferase deficiency. Metabolism 56:1179-1186
25. Wong H, Feber J, Chakraborty P, Drukker A, Filler G (2008) Novel HGPRT $293 \mathrm{~A}>\mathrm{G}$ point mutation presenting as neonatal acute renal failure. Pediatr Nephrol 23:317-321

26. Torres RJ, Puig JG (2007) Hypoxanthine-guanine phosphoribosyltransferase deficiency: Lesch-Nyhan syndrome. Orphanet J Rare Dis 2:48

27. Blau N, Duran M, Balkovics ME, Gibson KM (2003) Physician's guide to the laboratory diagnosis of inborn errors of metabolic diseases. Springer, Heidelberg

28. Di Pietro V, Perruzza I, Amorini AM, Balducci A, Ceccarelli L, Lazzarino G, Barsotti P, Giardina B, Tavazzi B (2007) Clinical, biochemical and molecular diagnosis of a compound homozygote for the $254 \mathrm{bp}$ deletion- $8 \mathrm{bp}$ insertion of the APRT gene suffering from severe renal failure. Clin Biochem 40:73-80

29. Ichida K, Amaya Y, Kamatani N, Nishino T, Hosoya T, Sakai O (1997) Identification of two mutations in human xanthine dehydrogenase gene responsible for classical type I xanthinuria. J Clin Invest 99:2391-2397

30. Online Mendelian Inheritance in Man. Available at http://www. ncbi/nlm.nih.gov/entrez/

31. Smit GPA, Rake JP, Akman HO, Di Mauro S (2006) The glycogen storage diseases and related disorders. In: Fernandes J, Saudubray JM, van den Berghe G, Walter JH (eds) Inborn metabolic diseases: diagnosis and treatment. Springer, Heidelberg, pp 101-119

32. Weinstein DA, Somers MJ, Wolfsdorf JI (2001) Decreased urinary citrate excretion in type 1a glycogen storage disease. J Pediatr 138:378-382

33. Simpson DP (1983) Citrate excretion: a window on renal metabolism. Am J Physiol 244:F223-F234

34. Brennan S, Hering-Smith K, Hamm LL (1988) Effect of pH on citrate reabsorption in the proximal convoluted tubule. Am J Physiol 255:F301-F306

35. Ristoff E, Larsson A, Jaeken J (2006) Disorders in the metabolism of glutathione and imidazole dipeptides. In: Fernandes J, Saudubray JM, van den Berghe G, Walter JH (eds) Inborn metabolic diseases: diagnosis and treatment. Springer, Heidelberg, pp 373-380

36. Pahari A, Milla PJ, van't Hoff WG (2003) Neonatal nephrocalcinosis in association with glucose-galactose malabsorption. Pediatr Nephrol 18:700-702

37. Laube GF, Leonard JV, van't Hoff WG (2003) Nephrocalcinosis and medullary cysts in 3-methylglutaconic aciduria. Pediatr Nephrol 18:712-713

38. Blue diaper syndrome. Available at www.orpha.net/consor/cgi-Bin

\section{Answers:}

1. a, d, e

2. c, e

3. b, c 